\title{
Üriner Sistem Taş Hastalığında Medikal Ekspulsif Tedavi: Kime, Nasıl, Ne Kadar?
}

\author{
Osman Ergün, Murat Gönen
}

Konya Eğitim ve Araştırma Hastanesi, Üroloji Kliniği, Konya

Giriş

$\dot{U}^{\bullet}$ riner sistem taş hastalığının tüm dünyada görülme sıklığ1 \%1-13 arasında değişen oranlarda bildirilmekledir. Üreter taşları tüm üriner sistem taşlarının yaklaşık \%20'sini oluşturmaktadır ve bu taşların da \%70'i anatomik olarak distal üreterde lokalizedir (1). Üriner sistem taş hastalığı erkeklerde kadınlara göre 2 kat daha fazla görülmekte ve kayda değer ekonomik kayba neden olmaktadır (2).

Üriner sistem taşlarının tedavisi; bulundukları anatomik lokalizasyona, boyutlarına ve oluşturdukları ek komplikasyonlara bağlı olarak değişiklik arz etmektedir. Üreter taşlarında tedavi seçenekleri; gözlem, medikal ekspulsif tedavi (MET), vücut dışı şok dalgası ile taş kırma (ESWL), perkütan antegrad üreteroskopi, retrograd üreteroskopi ve açık/laparoskopik üreterolitotomidir (3). Bu tedavi alternatiflerinden hangisinin uygulanacağı taşın lokalizasyonuna, taşın büyüklüğüne, mevcut teknolojiye, tedavi maliyetine, cerrahın deneyimine ve hastanın tercihine bağlıdır (4).

Yapılan bir metaanalizde $5 \mathrm{~mm}$ 'den küçük taşların \%68'inin kendiliğinden düşebileceğini ortaya konulmuştur. Bu oranın 5-10 mm arasındaki taşlarda \%47'ye düştüğü bildirilmiştir (5). Boyutundan bağımsız olarak taşın lokalizasyonu da kendiliğinden düşme ihtimalinde önemli bir faktördür. Proksimal üreter taşlarının \%22'si, orta üreter taşlarının $\% 46$ 's1, distal üreter taşlarının \%71'i kendiliğinden düşebilir (6). Semptomları kontrol altında tutulabilen, enfeksiyon bulguları olmayan küçük üreter taşlarında, taşın kendiliğinden düşmesinin beklenmesi iyi bir seçenek olarak bilinmektedir. Aynı zamanda hastayı invaziv cerrahi girişimlerden ve gereksiz maliyetlerden korumaktadır (7).

Üriner sistem taşlarının altında yatan fizyolojik ve patofizyolojik mekanizmaların daha iyi anlaşılması ile birlikte MET kavramı gelişmiştir. MET'deki amaç üreter peristaltizmini bozmadan üreterin düz kas yapısında gevşeme sağlamak, hastanın hissettiği ağrı şiddetini ve sıklığını düşürmek, taşa bağlı olarak üreter mukozasında oluşmuş olan ödem ve enflamasyonu azaltmak ve enfeksiyöz durum oluşumunu engellemektir. Bu amaçla çeşitli ilaç seçenekleri mevcuttur. Bunlar non-steroid antienflamatuar ilaçlar (NSAIİ), antimuskarinik ilaçlar, fosfodiesteraz tip-5 inhibitörleri, steroidler, kalsiyum kanal blokörleri ve alfa blokör ajanlardır.

Taşın düşmesine yardımcı olmak için uygulanan ilk tedavi modellerinde, taşın pasajı antiemetik ve analjezikler ile birlikte artmış sıvı alımı ile desteklenmekte idi. İnsan üreterindeki adrenerjik reseptörlerin yapısı ve düz kasların fizyolojisi hedefe yönelik medikal tedavinin gelişmesini sağlamıştır $(8,9)$. Üreterlerin, özellikle de distal 1/3'lük kısmı, alfa-1 reseptörlere sahip düz kas hücreleri ile kaplıdır. Bu reseptörlerin blokajı, hem bazal düz kas tonusunu; hem de koordinasyonsuz hiperperistaltik dalga sıklığını inhibe eder.

Alfa blokerler ve kalsiyum kanal blokerlerinin yararları ilk olarak hayvan modellerinde gösterilmiş, ardından yapılan pek çok randomize kontrollü çalışmalarla bu ilaçlar günlük pratiğimize girmiştir (10-12). Kalsiyum kanal blokerlerinin ve alfa blokerlerin kullanıldığ 9 randomize kontrollü çalışmanın değerlendirildiği bir meta analizde kalsiyum kanal blokeri veya alfa bloker kullanılan hastalarda taşın düşme ihtimalinin \%65 daha fazla olduğu $(\mathrm{p}<0.0001)$ ortaya konmuştur (2). MET'de kalsiyum kanal blokerlerinin mi yoksa alfa blokerlerin mi daha etkin olduğu konusunda literatürde farklı veriler bulunmaktadır. Bununla birlikte tüm veriler değerlendirildiğinde alfa blokerlerin daha üst seviyede yararlı oldukları görülmektedir (5). Ayrıca kalsiyum kanal blokerlerinin yan etki profilleri ve bu ilaçlara ürologların daha yabancı olduğu düşünüldüğünde alfa blokörler yarar bakımından bir adım öne geçmektedirler.

MET'de tüm alfa blokörlerin aynı etkiyi gösterip göstermediği araştırılmıştır. Alfuzosin kullanılan bir çalışmada taş düşme oranları bakımından plasebo (\%77.1) ve alfuzosin (\%73.5) grubu arasında istatistiki olarak anlamlı bir fark olmadığ 1 bildirilmiştir (13). Bununla birlikte araştırmac1lar alfuzosin grubunun daha az ağrı duyduğunu ve taş düşme sürelerinin daha kısa olduğunu tespit etmişlerdir. Ülkemizden Yılmaz ve ark.'ları tamsulosinin \%79.3, terazosinin \%78.5, doxazosinin \%75.8 başarı oranıyla taşın atılımını kolaylaştırdığını göstermişlerdir (14). Yine ülkemizden Gürbüz ve ark.'ları çalışmalarında üç değişik alfa blokeri Hyosin N-Butilbromid (HBB) ile karşılaştırmışlardır (15). Grup 1'e HBB, Grup 2'ye alfuzosin, Grup 3'e doksazosin ve Grup 4'e terazosin vermişlerdir. Grup 1, 2, 3, ve 4'deki taş düşürme oranlarını sırası ile $\% 11, \% 52.9, \% 62$, ve $\% 46$ olarak tespit etmişlerdir. Yine taşın düşmesine kadar geçen süreyi de aynı sıra ile 10.55, 7.38, 7.85, 7.45 gün olarak bildirmişlerdir. Sonuçta yazarlar, üç alfa blokerin de; HBB'den taş düşürme oranı ve düşme süresi açısından üstün olduklarını belirtmişlerdir.

Distal üreterde en yoğun bulunan alfa adrenerjik reseptör tipi $\alpha 1 D^{\prime}$ dir. Naftopidil ve silodosin spesifik $\alpha 1 \mathrm{D}$ reseptör blokeridir. Yapılan bir çalışmada $0.4 \mathrm{mg}$ tamsulosin + 
prednizolon ile $75 \mathrm{mg}$ naftopidil + prednizolon ve gözlem grubu ile karşılaştırılmıştır (16). Her iki grubun da istatistiki olarak anlamlı bir şekilde gözlem grubundan daha yüksek taş düşürme oranına sahip olduğu $(\mathrm{p}=0.002, \mathrm{p}<0.001)$ bildirilmiştir. Naftopidil grubunda taşsızlık oranı biraz yüksek gibi gözükse de; naftopidil ve tamsulosinin benzer taş pasaj oranlarına (\%87.5 ve \%70) sahip olduğu bildirilmiştir. Diğer taraftan Gupta ve ark.'ları ise; 100 hastalık çalışmalarında tamsulosin (Grup 1) ve silodosin (Grup 2)'in etkinliklerini karşılaştırmışlardır (17). Grup 1'de \%58'lik, Grup 2'de ise; $\% 82^{\prime}$ lik bir taş düşürme oranı bildirmişlerdir. Sonuçta yazarlar, Silodosin'in hem taşın düşürülmesinde hem de; pasaj süresinde tamsulosin'den üstün olduğunu bildirmişlerdir.

Kumar ve ark.'ları boyutu 5 ile $10 \mathrm{~mm}$ arası değişen distal üreter taşına sahip 62 hastaya tamsulosin (Grup A) ve tamsulosin + tadalafil (Grup B) vermişlerdir (18). Yazarlar, Grup A'da \%74.2, Grup B'de ise \%83.9'luk bir taş düşürme oranı bildirmişlerdir. Ancak aradaki fark istatistiksel olarak anlamlı olarak $(\mathrm{p}=0.349)$ tespit edilmemiştir. Bununla birlikte kolik nedeni ile hastanede yatış süresi ve analjezik gereksinimi Grup B'de daha az olarak tespit edilmiş ve aradaki farkın istatistiksel olarak anlamlı farklı olduğu bildirilmiştir.

Taş pasajinda gelişen ödemin önemli bir faktör olduğu düşünüldügünnde $\mathrm{MET}^{\prime}$ de glukokortikoidlerin kullanılması da kaçınılmaz olmuştur. Glukokortikoidler prostoglandin salınımını inhibe ederek taş tarafından oluşturulan ödemi ve enflamatuar reaksiyonu geriletebilir veya önleyebilirler. Klinik çalı̧̧malar glukortikoidlerin alfa blokörlerle veya kalsiyum kanal blokörleri ile kombine edilmesinin taş pasajina yardımcı olduğunu ortaya koymuştur $(19,20)$. Ancak glukortikoidler tek başlarına taş düşme oranını arttırmamaktadırlar (21).

ESWL tedavisi sonrası rezidü taşı kalanlarda da; MET denenmiştir. Janane ve ark.'ları ESWL tedavisi sonrası 356 hastayı kontrol (diclofenak) ve tamsulosin olmak üzere iki gruba randomize etmişlerdir (22). Grup 1'de taşsızlık oranı $\% 48.2$ ve Grup 2'de taşsızlık oranı \%77.4 ( $\mathrm{p}=0.002)$ olarak bildirilmiştir. Grup 1'deki taş düşme süresi 10.6 gün, Grup $2^{\prime}$ deki ise 8.4 gün olarak bildirilmiştir. Ülkemizden yapılan bir çalışmada ise Çakıroğlu ve ark.'ları ESWL tedavisi sonrası 123 hastayı kontrol ve tamsulosin olmak üzere iki gruba randomize etmişlerdir (23). Tamsulosin'in özellikle üst üreter taşları olmak üzere ESWL sonrası tüm üreter taşlarında, taş düşme süresini kısaltarak ve analjezik ihtiyacını azaltarak tedaviye yardımcı olduğunu bildirmişlerdir.

MET yetişkinlerin yanında, sınırlı olmakla birlikte çocuklarda da kullanılmıştır. Literatürde bu alanda yapılmış olan önemli çalışmalardan iki tanesi ülkemizde yapılmıştır. Erturhan ve ark.'ları 45 çocuğu ibuprofen ve ibuprofen ile birlikte doksazosin olmak üzere iki gruba randomize etmişlerdir (24). İbuprofen grubunda taş düşme oranı \%28.6 kombine grupta \%70.8 olarak tespit edilmiştir. Aynı zamanda kombine grupta ağrı atağı ve pasaj süresi daha az olarak tespit rapor edilmiştir. Aydoğdu ve ark.'ları distal üreter taşı olan 39 hastanın 19'una doksazosin ve ibuprofen, 20 hastaya ise yalnızca ibuprofen vermişlerdir (25). Doksazosin ile MET uygulanan hastaların \%84'ünde, yalnızca ibuprofen verilen hastaların \%70'inde taşın düştüğü gözlenmiş̧ir. Bu bulgular uygun çocuk hastalarda MET'nin kullanılabileceğini göstermektedir.

MET'nin ne kadar süre ile uygulanacağı, taşın düşmesi için ne kadar süre bekleneceği konusunda literatürde deği- şik veriler bulunmaktadır. Miller yaptığı çalışmada uygun hastalarda taşın düşmesi için 6 hafta beklenebileceğini bildirmiştir (26). Ancak klinik uygulamalarda her hekim farklı klinik yaklaşımlar geliştirebilmektedir. Ülkemizden Öztürk ve ark.'ları 2010 yılında yaptıkları bir çalışmada 106 üroloji asistanı ve uzmanının üreter taşlarına yaklaşımlarını öğrenmek amaciyla 11 soruluk bir form, her klinik için belirlenmiş bir hekim tarafından, ilgili klinikte doldurtulmuştur (27). Çalışmaya katılan hekimlerin \%83'ü MET olarak antienflamatuar analjezik kullandıklarını, \%90'ı alfa blokör ve \%5'i kortikosteroid tercih ettiklerini bildirmişlerdir. Hekimlerden hiçbiri bu amaçla kalsiyum kanal blokörü kullanmamaktadır. MET amacı ile alfa blokör kullanan hekimlerin \%57'si tamsulosin, \%16'si doksazosin, $\% 7^{\prime}$ si alfuzosin ve $\% 5^{\prime}$ i terazosin tercih ediyorken, \%6'sı alfa blokörler arasında tercih yapmadıklarını, herhangi bir alfa blokör seçtiklerini bildirmişlerdir. Hekimlerin \%14'ü bu tedaviyi 1 hafta, \%56's 2 hafta, \%16's1 3 hafta ve \%15'i 4 hafta süreyle verdiklerini bildirmişler, 5 hafta ve üzerinde tedavi verdiğini bildiren meslektaşımız olmamiştır.

MET uygun hasta grubunda efektif bir tedavi yaklaş1mıdır. On milimetre üzerindeki taşlarda ise MET yöntemi seçilmemelidir. Geçmeyen veya tekrarlayan ağrı, süreğen üriner obstrüksiyon, enfeksiyon, tek böbrek, böbrek yetmezliğinin eşlik ettiği veya etmediği elektrolit anormallikleri olan hastalarda MET uygun değildir. MET taş düşme oranlarını arttırmakta, taşın düşmesi için gereken süreyi azaltmakta, analjezik kullanım ihtiyacını azaltmakta ve hastaların hospitalizasyon sürelerini kısaltmaktadır.

\section{Kaynaklar}

1. Pak CY. Kidney stones. Lancet 351:1797-801,1998.

2. Hollingsworth JM, Rogers MA, Kaufman SR, Bradford TJ, Saint S, Wei JT, Hollenbeck BK. Medical therapy to facilitate urinary stone passage: a meta-analysis. Lancet 368:1171-9, 2006.

3. Crowley AR, Byrne JC, Vaughan ED Jr, Marion DN. The effect of acute obstruction on ureteral function. J Urol 143:596-9,1990.

4. Bensalah K, Pearle M, Lotan Y. Cost-effectiveness of medical expulsive therapy using alpha-blockers for the treatment of distal ureteral stones. Eur Urol 53:411-8,2008.

5. Preminger GM, Tiselius HG, Assimos DG, Alken P, Buck C, Gallucci M, Knoll T, Lingeman JE, Nakada SY, Pearle MS, Sarica K, Türk C, Wolf JS Jr. Guideline for the management of ureteral calculi. J Urol 178:2418-34,2007.

6. Morse RM, Resnick MI. Ureteral calculi: natural history and treatment in an era of advanced technology. J Urol 145:263-5,1991.

7. Lotan Y, Gettman MT, Roehrborn CG, Cadeddu JA, Pearle MS. Management of ureteral calculi: A cost comparison and decision making analysis. J Urol 167:1621-9,2002.

8. Malin JM, Jr, Deane RF, Boyarsky S. Characterisation of adrenergic receptors in human ureter. Br J Urol 42:1714,1970 .

9. Salman S, Castilla C, Vela NR. Action of calcium antagonists on ureteral dynamics. Actas Urol Esp 13:1502,1989.

10. Laird JM, Roza C, Cervero F. Effects of artificial calculosis on rat ureter motility: Peripheral contribution to the pain of ureteric colic. Am J Physiol 272:R1409-16,1997. 
11. Maggi CA, Giuliani S. A pharmacological analysis of calcium channels involved in phasic and tonic responses of the guinea-pig ureter to high potassium. J Auton Pharmacol 15:55-64,1995.

12. Sivula A, Lehtonen T. Spontaneous passage of artificial concretions applied in the rabbit ureter. Scan J Urol Nephrol 1:259-63,1967.

13. Pedro RN, Hinck B, Hendlin K, Feia K, Canales BK, Monga M. Alfuzosin Stone Expulsion Therapy for Distal Ureteral Calculi: A Double-Blind, Placebo Controlled Study. J Urol 179:2244-7,2008.

14. Yilmaz E., Batislam E., Basar MM. ve ark. The comparison and efficacy of 3 different alpha1-adrenergic blockers for distal ureteral stones. J Urol 173:2010-2012,2005.

15. Gürbüz MC, Polat H, Canat L, Kilic M, Caskurlu T. Efficacy of three different alpha 1-adrenergic blockers and hyoscine N-butylbromide for distal ureteral Stones. Int Braz J Urol 37(2):195-200,2011.

16. Kumar S, Kurdia KC, Ganesamoni R, Singh SK, Nanjappa B. Randomized Controlled Trial to Compare the Safety and Efficacy of Naftopidil and Tamsulosin as Medical Expulsive Therapy in Combination With Prednisolone for Distal Ureteral Stones. Korean J Urol 54(5):311-5,2013.

17. Gupta S, Lodh B, Singh AK, Somarendra K, Meitei KS, Singh SR. Comparing the efficacy of tamsulosin and silodosin in the medical expulsion therapy for ureteral calculi. J Clin Diagn Res 7(8):1672-4,2013.

18. Kumar S, Jayant K, Agrawal S, Singh SK. Comparative efficacy of tamsulosin versus tamsulosin with tadalafil in combination with prednisolone for the medical expulsive therapy of lower ureteric stones: a randomized trial. Korean J Urol 55(3):196-200,2014.

19. Salehi M, Fouladi Mehr M, Shiery H, Mokhtari G, Dejabad V. Does methylprednisolone acetate increase the success rate of medical therapy for passing distal ureteral stones? Eur Urol Suppl 4(3):25-25,2005.

20. Porpiglia F, Destefanis P, Fioric C, Fontana D. Effectiveness of nifedipine and deflazacort in the management of distal ureter stones. Urology 56: 579-582,2000.

21. Porpiglia F, Vaccino D, Billia M, Renard J, Cracco C, Ghignone G, Scoffone C, Terrone C, Scarpa RM. Corticosteroids and tamsulosin in the medical expulsive therapy for symptomatic distal ureter stones: single drug or association? Eur Urol 50:339-344,2006.

22. Janane A, Hamdoun A, Hajji F, Dakkak Y, Ghadouane M, Ameur A, Abbar M. Usefulness of adjunctive alpha1adrenergic antagonists after single extracorporeal shock wave lithotripsy session in ureteral stone expulsion Can Urol Assoc J 8(1-2):E8-E11,2014.

23. Basri Cakıroglu, Sinanoglu O, Mahmure Uraz. The effect of tamsulosin on pain and clearance according to ureteral stone location after shock wave lithotripsy. Curr Ther Res Clin Exp 74:33-5,2013.

24. Erturhan S, Bayrak O, Sarica K, Seckiner I, Baturu M, Sen H. Efficacy of medical expulsive treatment with doxazosin in pediatric patients. Urology 81:640-3,2013.

25. Aydogdu O, Burgu B, Gucuk A, Suer E, Soygur T. Effectiveness of doxazosin in treatment of distal ureteral stones in children. J Urol 182:2880-2884, 2009.

26. Miller OF, Kane CJ. Time to Stone passage for observed ureteral calculi: a guide for patient education. J Urol 162(3Pt1):688-90,1999.

27. Öztürk Mİ, Gürbüz C, Koca O, Sarıca K, Şenkul T, Yıldırım A, Eryıldırım B. Üreter taşı tanı ve tedavisinde güncel durum: İstanbul'dan kesitsel bir tarama. Türk Üroloji Dergisi 36(2):125-131,2010.

Yazışma Adresi:

Osman Ergün

Konya Eğitim ve Araştırma Hastanesi, Üroloji Kliniği,

Meram, Konya

Tel: +903322210000 / 1835

e-mail: osmanergun77@mynet.com 